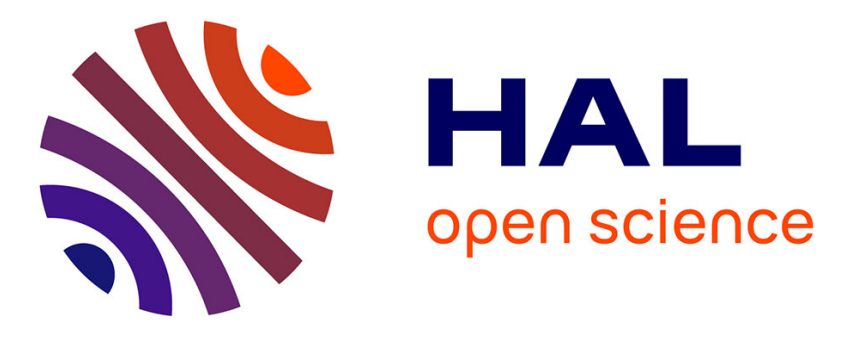

\title{
Developmental pharmacokinetics of etoposide in 67 children: lack of dexamethasone effect
}

Saik Urien, François Doz, Carole Giraud, Elisabeth Rey, Jean-Claude Gentet, Pascal Chastagner, Gilles Vassal, Nadège Corradini, Anne Auvrignon, Pierre Leblond, et al.

\section{To cite this version:}

Saik Urien, François Doz, Carole Giraud, Elisabeth Rey, Jean-Claude Gentet, et al.. Developmental pharmacokinetics of etoposide in 67 children: lack of dexamethasone effect. Cancer Chemotherapy and Pharmacology, 2010, 67 (3), pp.597-603. 10.1007/s00280-010-1357-2 . hal-00594500

\section{HAL Id: hal-00594500 \\ https://hal.science/hal-00594500}

Submitted on 20 May 2011

HAL is a multi-disciplinary open access archive for the deposit and dissemination of scientific research documents, whether they are published or not. The documents may come from teaching and research institutions in France or abroad, or from public or private research centers.
L'archive ouverte pluridisciplinaire HAL, est destinée au dépôt et à la diffusion de documents scientifiques de niveau recherche, publiés ou non, émanant des établissements d'enseignement et de recherche français ou étrangers, des laboratoires publics ou privés. 


\section{DEVELOPMENTAL PHARMACOKINETICS OF ETOPOSIDE IN 67 CHIDREN - LACK OF DEXAMETHASONE EFFECT}

Saik URIEN ${ }^{1,2}$, François $\mathrm{DOZ}^{2,3}$, Carole GIRAUD ${ }^{1,2}$, Elisabeth REY ${ }^{2,4,5}$, Jean-Claude GENTET ${ }^{6}$, Pascal CHASTAGNER ${ }^{7}$, Gilles VASSAL ${ }^{8}$, Nadège CORRADINI ${ }^{9}$, Anne AUVRIGNON $^{10}$, Pierre LEBLOND ${ }^{11}$, Hervé RUBIE ${ }^{12}$, Jean-Marc TRELUYER ${ }^{1,2,4}$

1) CIC-0901 Inserm Necker-Cochin and EA-3620

2) Université Paris Descartes

3) Département de pédiatrie, Institut Curie

4) Pharmacologie, Hopital Cochin-saint-Vincent-de-Paul, Paris

5) Inserm U663

6) Hopital d'Enfants, CHU Timone, Marseille

7) Hopital d'Enfants, CHU Nancy, Nancy

8) Institut Gustave Roussy, Villejuif

9) Hopital Hotel Dieu, Nantes

10)Hopital Trousseau, Paris

11) Centre Oscar Lambret, Lille

12) Unité d'Hémato-Oncologie, Hôpital des Enfants, Toulouse 
Page $\quad 2 / 18$

Short running title: Dexamethasone effect on etoposide kinetics in children

\section{CORRESPONDENCE}

Dr Saik URIEN

Unité de Recherche Clinique

Hopital Tarnier

89 rue d'Assas

75006 Paris, france

saik.urien@svp.aphp.fr

Tel. +33158412880

Fax +33158411183

Key Words: etoposide, dexamethasone, population pharmacokinetics, children, anticancer drugs, genetic polymorphisms 


\section{Abstract}

Purpose: A randomized clinical trial examined whether dexamethasone administration prior to odansetron followed by etoposide and carboplatin infusions, and singlenucleotide polymorphisms (SNPs) of CYP3A4, CYP3A5 and MDR1 genes could modify etoposide pharmacokinetics in pediatric patients.

Methods: Patients, 67 children, aged 14 weeks to 16.7 years, were treated for various malignancies and received either 3- or 5-days courses of etoposide and carboplatin: these two drugs were always administered after odansetron infusion but combined or not to dexamethasone $5 \mathrm{mg} / \mathrm{m}^{2} /$ day $30 \mathrm{~min}$ prior to etoposide infusion. Population pharmacokinetics was modelled using a non linear mixed effect model program (Monolix version 31s).

Results: Etoposide pharmacokinetics was ascribed to a 2-compartment model. The most significant covariate effect was bodyweight (BW), so the parameters were standardized to a $70 \mathrm{~kg} \mathrm{BW}$ using the allometric $3 / 4$ or 1 power model for clearance (CL, Q) or volume terms $(\mathrm{V})$, respectively. The population means for clearance and central volume of distribution were $2.05 \mathrm{~L} / \mathrm{h} / 70 \mathrm{~kg}$ and $9.21 \mathrm{~L} / 70 \mathrm{~kg}$ with the corresponding between-subject variabilities, 0.26 and 0.28 . Dexamethasone treatment had no effect on $\mathrm{CL}$, either at the first or last administration occasion. CYP3A and MDR1 examined SNPs had no significant effect.

Conclusion: Pharmacokinetics of etoposide was influenced by BW on an allometric basis in this pediatric population. Dexamethasone did not influence etoposide pharmacokinetics during these 3 to 5 days courses. These results should allow a better individualisation of etoposide dosing in children. 


\section{Introduction}

Chemotherapy combining etoposide and carboplatin has been proven effective in the treatment of children with various cancer diseases, including medulloblastoma (1), neuroblastoma (2), nephroblastoma (3) and retinoblastoma (4). This highly potent chemotherapy is often associated to nausea and vomiting in children during and after the treatment period. The prevention of these adverse effects in children usually includes a combination of dexamethasone and odansetron (5). However, as etoposide is Odemethylated by cytochromes P450 (CYP) CYP3A4 and CYP3A5, dexamethasone could influence etoposide elimination via some effects on these CYPs (6). Moreover, singlenucleotide polymorphisms (SNPs) in CYP3A4 and CYP3A5 genes may modify enzymatic activity and then influence etoposide drug elimination rate. Indeed, a decrease of CYP3A4 activity has been associated with a SNP in the 5'-regulatory region of the CYP3A4 gene $(-392 A>G)$, named CYP3A*1B. Besides, the frequent SNP in intron 3 of the CYP3A5 gene $\left(\mathrm{CYP} \mathrm{C}^{\star}{ }^{\star}\right)$ results in an inactive truncated protein $(7,8)$. Furthermore, as etoposide is a substrate of the P-glycoprotein, encoded by the MDR1 gene, MDR1 gene SNPs could also modify etoposide disposition (9).

The objectives of this study were then to develop a population pharmacokinetic model for etoposide in pediatric patients and to examine a possible dexamethasone effect on etoposide elimination, including the research of other covariates as well as the effects of the SNPs of CYP3A4, CYP3A5 and MDR1 genes on etoposide clearance.

\section{Methods}

This randomized open clinical trial examined whether dexamethasone could modify 
etoposide pharmacokinetics in pediatric patients. All children had a documented cancer and were randomly allocated to either the single odansetron or the combined odansetron-dexamethasone antiemetic therapy group. This study was approved by the regional ethics committee and written consent had to be obtained from the parents before inclusion. Appropriate information had to be given to patients according to their age and assent of the oldest children and adolescents was necessary before study initiation. Patients aged 3 months to 16 years with a bodyweight greater than $4.5 \mathrm{~kg}$ and receiving the etoposide/carboplatin chemotherapy were eligible.

Patients received a 1 -h etoposide infusion followed by a 1 -h carboplatin infusion on 3 or 5 successive days (three-day chemotherapy: etoposide $150 \mathrm{mg} / \mathrm{m}^{2} /$ day etoposide and $200 \mathrm{mg} / \mathrm{kg} /$ day carboplatin, except for children $<1$ year old or $<10 \mathrm{~kg}, 5 \mathrm{mg} / \mathrm{kg} /$ day etoposide and $6.7 \mathrm{mg} / \mathrm{kg} /$ day carboplatin ; five-day chemotherapy: etoposide 100 $\mathrm{mg} / \mathrm{m}^{2} /$ day etoposide and $160 \mathrm{mg} / \mathrm{m}^{2} /$ day carboplatin, except for children $<1$ year old or $<10 \mathrm{~kg}, 3.3 \mathrm{mg} / \mathrm{kg} /$ day etoposide and $5.3 \mathrm{mg} / \mathrm{kg} /$ day carboplatin). Thirty minutes prior to chemotherapy, patients received odansetron $5 \mathrm{mg} / \mathrm{m}^{2} / \mathrm{day}$ combined or not to dexamethasone $5 \mathrm{mg} / \mathrm{m}^{2} /$ day.

For most patients, two pharmacokinetic evaluations took place on the first and last day of chemotherapy. Four sampling times per evaluation were randomly drawn from the following set : 5, 15, $30 \mathrm{~min}, 1,2,3,4,5,6,7,8,9,10,11 \mathrm{~h}$ following the end of infusion. Blood samples were immediately centrifuged to yield plasma. Etoposide was essayed in $100 \mu \mathrm{L}$ plasma samples by high-performance liquid chromatography with teniposide as internal standard and fluorometric detection according to a validated method (10). The limit of quantification was $0.1 \mathrm{mg} / \mathrm{L}$. 
$D N A$ extraction and genotyping. Blood samples were collected for genotyping after obtaining a written informed consent by the parents. Genomic DNA was extracted from peripheral blood leukocytes using the Blood Mini Kit DNA (Qiagen, Courtaboeuf, France) according to standard protocols, and stored at $-80^{\circ} \mathrm{C}$ until use. For the SNPs $6986 \mathrm{~A}>\mathrm{G}$ of CYP3A5 gene (CYP3A5*3; rs776746), 2677G>T/A (exon 21; rs2032582) and $3435 \mathrm{C}>\mathrm{T}$ (exon 26; rs1045642) of MDR1 gene, alleles were determined by using Taq Man® Assay Reagents and probes for allelic discrimination (TaqMan® SNP Genotyping Assays, Applied Biosystems, Courtaboeuf, France) with a 7900HT Applied Biosystems thermal cycler. For the SNP $-392 \mathrm{~A}>\mathrm{G}$ of CYP3A4 (CYP3A4*1B; rs2740574), primers and probe set were designed using the custom TaqMan® SNP Genotyping Assays Service (Applied Biosystems). Sequences are available upon request.

Population pharmacokinetic modelling. Data were analysed using the nonlinear mixed effect modelling software program Monolix version 31s (http://wfn.software.monolix.org). Parameters were estimated by computing the maximum likelihood estimator of the parameters without any approximation of the model (no linearization) using the stochastic approximation expectation maximization (SAEM) algorithm combined to a MCMC (Markov Chain monte Carlo) procedure. The number of MCMC chains was fixed to 5 for all estimations. A proportional model was used to describe the residual variability, and the between-subject variabilities (BSV) were ascribed to an exponential model. Parameter shrinkage was calculated as $\{1$ sd(eta)/omega\}, where sd(eta) and omega are the standard deviation of individual eta parameters and the population model estimate of the BSV respectively. For the SNPs of CYP3A4, CYP3A5 and MDR1 genes, all the genotypes effects (9 parameters) were 
estimated together relative to the wild type (baseline $C L$ ). Then at each successive step the genotype effect with the less significant parameter (with the greatest $p$ value) was removed. Moreover, the Likelihood Ratio Test (LRT) including the log-likelihood, the Akaike information criterion (AIC) and the bayesian information criterion (BIC) was used to test different hypotheses regarding the final model, covariate effect on pharmacokinetic parameter(s), residual variability model (proportional versus proportional plus additive error model), structure of the variance-covariance matrix for the BSV parameters. Diagnostic graphics and other statistics were obtained using the $\mathrm{R}$ program (12).

\section{Results}

From the 67 patients investigated, 566 time-plasma concentrations were available for analysis. Nine concentrations were reported below the limit of quantification (BLQ) and considered as left-censored data in the modelling process. Patients characteristics are summarized in Table 1.

A two-compartment open model adequately described etoposide data. BSV was estimated for all structural parameters with a covariance term between the clearance (CL) and central volume of distribution (Vc). Residual variability was described by a proportional error model. At this step, CL was $0.69 \mathrm{~L} / \mathrm{h}$ (relative standard error, rse $7 \%$ ) per a mean $20.6 \mathrm{~kg}$ BW and the corresponding BSV was 53\% (rse 2\%).

The main covariates effects on all pharmacokinetic parameters were BW and age (Fig. 1), so the pharmacokinetic parameters were allometrically normalized for BW to a $70 \mathrm{~kg}$ individual as follows,

$$
\mathrm{Pi}=\mathrm{P}_{\text {TYPICAL }} \times(\mathrm{BWi} / 70)^{\mathrm{PWR}},
$$

Urien et al. 15:05, 06/05/10 
where $\mathrm{i}$ denotes the ith individual. The PWR exponents were $3 / 4$ and 1 for the clearance and volume terms respectively. This significantly decreased all BSV estimates (BSV of CL decreased from $53 \%$ to $28 \%$ ) and improved the predictive performance of the model (observed concentrations versus model predicted concentrations). Thereafter, an additional age effect was investigated using a sigmoid Emax model relating the postmenstrual age $(\mathrm{PMA}=$ post-natal age +40 weeks $)$ to a fractional value for mature clearance, $F_{P M A}=\mathrm{PMA}^{h} /\left(\mathrm{PMA}^{\mathrm{h}}{ }^{h}+\mathrm{PMA}^{h}\right)$, where $\mathrm{PMA}_{50}$ is the $\mathrm{PMA}$ at which $\mathrm{F}_{\mathrm{PMA}}=0.5$ and $h$ is the Hill coefficient. This did not improve the model, and the $\mathrm{PMA}_{50}$ and $\mathrm{h}$ estimates were not significant with much more than $50 \%$ relative standard errors. The effect of age was finally removed by the BW allometric scaling.

The dexamethasone effect on etoposide $C L$ was allowed to be different on the first and second occasion ( 3 to 5 days later). Without dexamethasone (control treatment) etoposide $C L$ estimates on the $1^{\text {st }}$ and $2^{\text {nd }}$ occasions were not significantly different. Thereafter, there was no significant difference between etoposide CL estimates without or with a previous infusion of dexamethasone, on the $1^{\text {st }}$ or $2^{\text {nd }}$ occasion, the $C L$ variations relative to the control were lower than $2 \%$.

Table 2 shows the distribution of CYP3A4, CYP3A5 and MDR1 genotypes in the 67 children. No significant effects of CYP3A4, CYP3A5 or MDR1 gene SNPs on etoposide pharmacokinetics were observed. There was a trend in CL increase, $+9 \%$, in patients with the CYP3A5 $5^{*}{ }^{*} 3$ genotype (Wald test, $p=0.09, n=10$ patients in this group).

Table 3 summarizes the final population pharmacokinetic estimates. Most of the parameters were well estimated with low relative standard errors. The empirical Bayesian estimate shrinkages were generally low, only the peripheral pharmacokinetic parameters, $Q$ and $V p$ had shrinkage estimates between 20 and $25 \%$. 
The results of the visual predictive check (VPC) are depicted in Fig. 2. The patients received generally a dose normalised by size. Therefore the VPCs were finally stratified according to the first and last infusion, respectively. For all groups, the observed concentrations were centered about the model-predicted median and the proportion of observations out of the model-predicted $5^{\text {th }}$ and $95^{\text {th }}$ percentile curves were not significantly different from $10 \%$.

Based on individual etoposide clearance estimates and drug dosages, the mean total etoposide exposure (area under the curve or AUC) was $371( \pm 94)$ or $474( \pm 127)$ $\mathrm{mg} . \mathrm{h} / \mathrm{L}$ for the 3- or 5-day chemotherapy respectively (significant difference, KruskalWallis rank sum test $p=0.0003$ ). Given the significant relationship between clearance and bodyweight, the etoposide dosage targetting these drug exposures, 371 and 474 mg.h/L, were compared to the actual drug exposure. Figure 3 shows the great variability achieved in etoposide exposure with the actual dosage, particularly for the smallest, youngest, patients and the difference between the actual drug dosage and a candidate drug dosage aimed to target the same AUC for each therapeutic modality (Dose = 2.05.(BW/70) $\left.)^{3 / 4} \cdot \mathrm{AUC}_{\text {target }}\right)$.

\section{Discussion}

The pharmacokinetics of plasma etoposide in pediatric patients was satisfactorily described by an open two-compartmental model with linear elimination. The administration of dexamethasone in addition to odansetron as antiemetic therapy, prior to etopside-carboplatin infusions, had no significant effect on etoposide CL. The etoposide $\mathrm{CL}$ estimate, $2.05 \mathrm{~L} / \mathrm{h} / 70 \mathrm{~kg}$ was close to previously reported estimates in adult patients, $1.8 \mathrm{~L} / \mathrm{h}(13)$ or $2.65 \mathrm{~L} / \mathrm{h}(14)$, supporting the BW allometric scaling of pharmacokinetic 
parameters. Moreover in a population of 18 infants aged $2.5-14$ months (median 10 months), the estimated $\mathrm{CL}$ was $6.3 \mathrm{~mL} / \mathrm{min} / 8 \mathrm{~kg}$ or $0.38 \mathrm{~L} / \mathrm{h} / 8 \mathrm{~kg}(15)$, which according to the BW allometric scaling will be $0.38 \times(70 / 8)^{3 / 4}=1.92 \mathrm{~L} / \mathrm{h} / 70 \mathrm{~kg}$. Also, in 45 pediatric patients aged $0.5-17.7$ years, the estimated $\mathrm{CL}$ was 17.1 or $17.6 \mathrm{~mL} / \mathrm{min} / \mathrm{m}^{2}$ according to two age groups, corresponding to 1.84 or $1.90 \mathrm{~L} / \mathrm{h} / 1.8 \mathrm{~m}^{2}(16)$.

In developmental pharmacokinetic approaches, an effect of age on CL could generally be observed in addition to the BW allometric scaling (17). This age effect explains a part of the CL maturation that is not dependent upon BW. However, in pediatric population, the age-related effect independent of size effect cannot always be established. The reasons are generally a too small sample size or a lack of data in age group below 1 year, in which age group the age-related CL maturation is very fast. In our study, only 8 patients were less than 1 year old, and only 2 were less than 6 months old.

No effect of prior dexamethasone administration on this short chemotherapy time period was observed. Kishi et al. (18) observed an increase in etoposide CL after a 29day period of prednisone treatment, but could not definitively attribute this effect to an induction of CYP3As. Since several days of drug exposition are required to observe induction of CYPs and transporters (involving transcription and protein traduction), the 3 to 5 days exposition to dexamethasone in the present study appears to be too short to increase etoposide clearance.

Among other covariates, the CYP3A5*1*3 genotype was associated to a trend in $C L$ increase (not significant). The CYP3A4 ${ }^{*} 1 A^{*} 1 B$ and ${ }^{*} 1 B^{*} 1 B$ genotypes included only 4 and 2 patients, respectively, and did not allow to show any significant CL changes in this population of 67 children. Finally, the lack of effect of MDR1 gene SNPs are in accordance with the results of Tran et al. for docetaxel disposition (19). Conversely, Kishi 
et al. showed that MDR1 exon $26 \mathrm{CC}$ genotype predicted higher day etoposide clearance. This discrepancy may be associated to a higher statistical power (greater number of patients) in their study (18).

Finally, there was a great variability in the achieved etoposide exposure, particularly in the youngest patients. This variability in exposure could be decreased if the drug dosage was aimed to target a particular exposure value, according to the patient clearance expected from bodyweight.

In conclusion, pharmacokinetics of etoposide was influenced by bodyweight on an allometric basis in this pediatric population. Dexamethasone did not influence etoposide pharmacokinetics. These results should allow a better individualisation of etoposide dosing in children and the safe use of dexamethasone as an anti-emetic drug when etoposide is combined to carboplatin.

\section{ACKNOWLEDGEMENTS}

We acknowledge Maryline Delattre, the clinical research assistants and the nurses for their time and dedication to this study. We also acknowledge the young patients and their families who participated to this trial with no direct benefit for themselves. 


\section{References}

1 Gentet JC, Doz F, Bouffet E, Plantaz D, Roché H, Tron P, Kalifa C, Mazingue F, Sariban E, Chastagner P, et al (1994) Carboplatin and VP 16 in medulloblastoma: a phase II Study of the French Society of Pediatric Oncology (SFOP). Med Pediatr Oncol 23:422-7.

2 Frappaz D, Michon J, Hartmann O, Bouffet E, Lejars O, Rubie H, Gentet JC, Chastagner P, Sariban E, Brugiere L, et al (1992) Etoposide and carboplatin in neuroblastoma: a French Society of Pediatric Oncology phase II study. J Clin Oncol 10:1592-601

3 Pein F, Tournade MF, Zucker JM, Brunat-Mentigny M, Deville A, Boutard P, Dusol F, Gentet JC, Legall E, Mechinaud F, et al (1994) Etoposide and carboplatin: a highly effective combination in relapsed or refractory Wilms' tumor--a phase II study by the French Society of Pediatric Oncology. J Clin Oncol 12:931-6.

4 Lumbroso-Le Rouic L, Aerts I, Lévy-Gabriel C, Dendale R, Sastre X, Esteve M, Asselain B, Bours D, Doz F, Desjardins L (2008) Conservative treatments of intraocular retinoblastoma. Ophtalmology $115: 1405-1410$.

5 Hesketh PJ, Harvey WH, Harker WG, Beck TM, Ryan T, Bricker LJ, Kish JA, Murphy WK, Hainsworth JD, Haley B (1994) A randomized, double-blind comparison of intravenous ondansetron alone and in combination with intravenous dexamethasone in the prevention of high-dose cisplatin-induced emesis. J Clin Oncol 12:596-600.

6 Relling MV, Nemec J, Schuetz EG, Schuetz JD, Gonzalez FJ, Korzekwa KR (1994) O-demethylation of epipodophyllotoxins is catalyzed by human cytochrome P450 3A4. Mol Pharmacol 45:352-8.

7 Kuehl P, Zhang J, Lin Y, Lamba J, Assem M, Schuetz J, Watkins PB, Daly A, 
Wrighton SA, Hall SD, Maurel P, Relling M, Brimer C, Yasuda K, Venkataramanan R, Strom S, Thummel K, Boguski MS, Schuetz E (2001) Sequence diversity in CYP3A promoters and characterization of the genetic basis of polymorphic CYP3A5 expression.Nat Genet 27:383-91.

8 Lakhman SS, Ma Q, Morse GD (2009) Pharmacogenomics of CYP3A: considerations for HIV treatment. Pharmacogenomics 10:1323-39.

9 Pariante CM (2008) The role of multi-drug resistance p-glycoprotein in glucocorticoid function: studies in animals and relevance in humans Eur J Pharmacol 583:263-71. 10 Liliemark E, Pettersson B, Peterson C, Liliemark J (1995) High-performance liquid chromatography with fluorometric detection for monitoring of etoposide and its cisisomer in plasma and leukaemic cells. J Chromatogr B Biomed Appl 669:311-7.

11 Kuhn E, Lavielle M (2005) Maximum likelihood estimation in nonlinear mixed effects models. Comput. Stat. Data Analysis 49:1020-30.

12 R Development Core Team. R (2009) A language and environment for statistical computing. R Foundation for Statistical Computin, Vienna, Austria.

13 Nguyen L, Chatelut E, Chevreau C, Tranchand B, Lochon I, Bachaud JM, Pujol A, Houin G, Bugat R, Canal P (1998) Population pharmacokinetics of total and unbound etoposide. Cancer Chemother Pharmacol 41:125-32.

14 Freyer G, Tranchand B, Ligneau B, Ardiet C, Souquet PJ, Court-Fortune I, Riou R, Rebattu P, Boissel JP, Trillet-Lenoir V, Girard P (2000) Population pharmacokinetics of doxorubicin, etoposide and ifosfamide in small cell lung cancer patients: results of a multicentre study. Br J Clin Pharmacol 50:315-24.

15 Veal GJ, Cole M, Errington J, Pearson ADJ, Gerrard M, Whyman G, Ellershaw C, Boddy AV (2009) Pharmacokinetics of carboplatin and etoposide in infant 
neuroblastoma patients. Cancer Chemother Pharmacol on line Aug 29.

16 Palle J, Frost BM, Gustafsson G, Hellebostad M, Kanerva J, Liliemark E, Schmiegelow K, Lönnerholm G (2006) Etoposide pharmacokinetics in children treated for acute myeloid leukemia.Anticancer Drugs 17:1087-94.

17 Anderson BJ, Holford NHG (2008) Mechanism-based concepts of size and maturity in pharmacokinetics. Ann. Rev. Pharmacol. Toxicol 48:303-332.

18 Kishi S, Yang W, Boureau B, Morand S, Das S, Chen P, Cook EH, Rosner GL, Schuetz E, Pui CH, Relling MV (2004) Effects of prednisone and genetic polymorphisms on etoposide disposition in children with acute lymphoblastic leukemia. Blood 103:67-72.

19 Tran A, Jullien V, Alexandre J, Rey E, Rabillon F, Girre V, Dieras V, Pons G, Goldwasser F, Tréluyer JM (2006) Pharmacokinetics and toxicity of docetaxel: role of CYP3A, MDR1, and GST polymorphisms. Clin Pharmacol Ther 79:570-80. 
Table 1

Characteristics of the 67 pediatric patients

\begin{tabular}{lllll}
\hline Item & $\mathrm{n}$ & Mean & Median & Range \\
\hline Age (year) & 67 & 5.35 & 3.52 & $0.27-16.7$ \\
Bodyweight $(\mathrm{kg})$ & & 20.6 & 15 & $5.3-66$ \\
Height $(\mathrm{cm})$ & & 105 & 100 & $60-172$ \\
Serum creatinine $(\mu \mathrm{M})$ & & 48 & 79 & $15-650$ \\
Total bilirubin $(\mu \mathrm{M})$ & & 6.7 & 6.0 & $2-17$ \\
Tumor type & & & & \\
-medulloblastoma & 18 & & & \\
-neuroblastoma & 26 & & & \\
-nephroblastoma & 7 & & & \\
-retinoblastoma & 5 & & & \\
-miscellanous & 11 & & \\
\hline
\end{tabular}


Table 2

Genotypes of CYP3A4, CYP3A5 and MDR1 in 67 pediatric patients

\begin{tabular}{|c|c|c|c|}
\hline & CYP3A5*3*3 & CYP3A5 ${ }^{*}{ }^{*} 3$ & CYP3A5 ${ }^{*}{ }^{*} 1$ \\
\hline CYP3A4 ${ }^{*} 1 A^{*} 1 \mathrm{~A}$ & 55 & 6 & 0 \\
\hline CYP3A4 ${ }^{*} 1 A^{*} 1 \mathrm{~B}$ & 1 & 3 & 1 \\
\hline CYP3A4 ${ }^{*} 1 \mathrm{~B}^{*} 1 \mathrm{~B}$ & 0 & 1 & \\
\hline & & & 2 \\
\hline MDR1 2677 GG & 16 & MDR1 3435 CT & MDR1 3435 TT \\
\hline MDR1 2677 GA & 1 & 5 & 7 \\
\hline MDR1 2677 GT & 1 & 0 & 7 \\
\hline MDR1 2677 TT & 0 & 26 & 2 \\
\hline
\end{tabular}




\section{Table 3}

Parameter estimates of the final etoposide population model in 67 pediatric patients (14 weeks -16.7 years). Parameters are normalized after a $70 \mathrm{~kg}$ patient according to allometric scaling

\begin{tabular}{|l|l|c|c|}
\hline Parameter & Covariate effect & Estimate (\%rse) & BSV (\%rse) [shrinkage] \\
\hline $\mathrm{CL}_{70}(\mathrm{~L} / \mathrm{h} / 70 \mathrm{~kg})$ & $\mathrm{CL}=\mathrm{CL}_{70}(\mathrm{BWi} / 70)^{3 / 4}$ & $2.05(4)$ & $0.27(9)[0.04]$ \\
\hline $\mathrm{Vc}_{70}(\mathrm{~L} / 70 \mathrm{~kg})$ & $\mathrm{Vc}=\mathrm{CL}_{70}(\mathrm{BWi} / 70)^{1}$ & $9.3(5)$ & $0.28(15)[0.19]$ \\
\hline $\mathrm{Q}_{70}(\mathrm{~L} / \mathrm{h} / 70 \mathrm{~kg})$ & $\mathrm{Q}=\mathrm{CL}_{70}(\mathrm{BWi} / 70)^{3 / 4}$ & $0.68(15)$ & $0.96(10)[0.21]$ \\
\hline $\mathrm{Vp} \mathrm{p}_{70}(\mathrm{~L} / 70 \mathrm{~kg})$ & $\mathrm{Vp}=\mathrm{CL}_{70}(\mathrm{BWi} / 70)^{1}$ & $5.7(8)$ & $0.53(13)[0.23]$ \\
\hline Residual & $\mathrm{NA}$ & Proportional & $0.222(4)[0.12]$ \\
variability & & & \\
\hline
\end{tabular}

Key : \%rse, percent relative standard error ; BSV, between-subject variability ; CL and Q, elimination and intercompartmental clearances; $V_{c}$ and $\mathrm{Vp}$, central and peripheral volumes of distribution; the subscript "70" indicates the parameter estimates are normalized to a $70 \mathrm{~kg}$ bodyweigth ; BWi, individual bodyweight. The correlation between $\mathrm{CL}$ and $\mathrm{Vc}$ BSVs is 0.89 . Accordingly, the expected $\mathrm{CL}$ for a patient weighing $15 \mathrm{~kg}$ is $2.05 \times(15 / 70)^{3 / 4}=0.75 \mathrm{~L} / \mathrm{h}$. 


\section{Figure legends}

Fig 1

Relationships between the empirical Bayes estimates (EBE) of etoposide clearance, in $\mathrm{L} / \mathrm{h}$, from the basic model and bodyweight (BW in $\mathrm{kg}$ ) and age (years) in 67 pediatric patients. The dashed lines are drawn after a spline function. The median of EBE clearance estimates is $0.74 \mathrm{~L} / \mathrm{h}$ (range $0.21-1.84$ ).

Fig 2

Visual predictive check for the final etoposide population model in 67 children (14 weeks - 17 years). Panels ADM.1 and ADM.2 denote the first etoposide or the second etoposide administration. The solid lines lines stand for the median, $5^{\text {th }}$ and $95^{\text {th }}$ percentiles of the simulated concentrations from the final model. The dashed lines lines stand for the median, $5^{\text {th }}$ and $95^{\text {th }}$ percentiles of the observed concentrations. Symbols * denote the concentrations reported below the limit of quantification.

Fig 3

Etoposide exposure (AUC) achieved on a 3-day or 5-day chemotherapy (TOP) and etoposide total dose on a 3-day or 5-day chemotherapy : (0, solid line) actual dose received or (+, dashed line) dose based on a target AUC (BOTTOM), versus patient bodyweight (BW). Etoposide exposure is determined as AUC $=$ (total dose)/(individual clearance) and the dose based on a target AUC is determined as $D=2.05$. $(B W / 70)^{3 / 4}$. AUC (371 and $474 \mathrm{mg} \cdot \mathrm{h} / \mathrm{L}$ for the 3-day or 5-day chemotherapy). The lines are drawn after a spline function. 